\title{
Ocorrência de Escherichia coli 0157:H7 e 026 sorbitol negativas em matadouro frigorífico de bovino e suscetibilidade a antimicrobianos
}

\author{
Occurrence of Escherichia coli 0157:H7 and 026 sorbitol negative in a cattle \\ slaughterhouse and susceptibility to antimicrobials
}

\author{
Natália Maramarque Nespolo ${ }^{1 *}$, Rachel Zoccal Saba', Dalila Aparecida Rossatelli' \\ John Morris Fairbrother ${ }^{2}$, Oswaldo Durival Rossi Júnior ${ }^{1}$
}

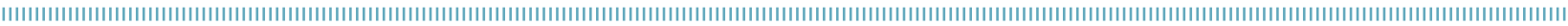

\begin{abstract}
RESUMO: A carne bovina pode ser um meio de transmissão de Escherichia coli $\mathrm{O} 157: \mathrm{H} 7$ e de não-O157 para os humanos, que a ingerem mal cozida, sendo responsáveis por causarem doenças severas, como a síndrome hemolítico urêmica. A resistência bacteriana se tornou preocupante em relação à eficácia nos tratamentos das doenças, e tendo em vista tais aspectos este estudo teve os objetivos de verificar a ocorrência de E. coli O157:H7 e não-O157 em etapas do abate bovino, asssim como de avaliar a suscetibilidade dessas bactérias frente à ação de antimicrobianos. Foram colhidas em abatedouro bovino 21 amostras de superfície de mãos dos manipuladores, 21 de facas e 300 provenientes de 50 animais em seis pontos no fluxograma de abate. O isolamento foi realizado utilizando o ágar CT-SMAC e a caracterização dos sorotipos pela PCR. Houve uma ocorrência maior de $E$. coli O157:H7 (12,0\%) nos animais, e menor ocorrência de E. coli O26 $(8,0 \%)$ e de $\mathrm{O} 113$ (2,0\%). E. coli $\mathrm{O} 26$ esteve presente em $9,52 \%$ das facas. A presença de $E$. coli náo-O157 sorbitol negativa foi um fato inesperado devido ao método de isolamento utilizado. Todos os isolados de E. coli $\mathrm{O} 157: \mathrm{H} 7$ mostraram-se sensíveis à tetraciclina, cefepime, cefoxitina, ciprofloxacina e sulfazotrim, e 78,85\% deles foram resistentes à cefalotina e 34,61\% à ampicilina. Todas E. coli $\mathrm{O} 26$ foram sensíveis ao cefepime, cefoxitina e sulfazotrim, e $88,23 \%$ resistentes à tetraciclina e cefalotina e $82,35 \%$ à ampicilina. A multirresistência aos antibimicrobianos foi observada em todos os sorotipos, devendo, portanto, haver critérios no uso de antimicrobianos nos tratamentos para não se tornar um problema de saúde pública.
\end{abstract}

PALAVRAS-CHAVE: Escherichia coli; matadouro frigorífico de bovino; antimicrobianos.

\begin{abstract}
Cattle beef could be a way of transmitting Escherichia coli O157: H7 and non-O157 to humans if they consume undercooked meat, being responsible for causing severe diseases such as hemolytic uremic syndrome. Bacterial resistance has become worrying concerning the efficacy in the treatment of diseases, and because of these aspects, the objective of this study was to verify the occurrence of E. coli O157: H7 and non-O157 in the stages of cattle slaughter and to evaluate the susceptibility of these bacteria against antimicrobial action. We collected from a cattle slaughterhouse 21 samples from manipulators' hands, 21 from knives and 300 from 50 animals in six points of the flowchart. The isolation was performed using the CT-SMAC agar and characterization of serotypes by PCR. There was higher occurrence of E. coli O157: $\mathrm{H} 7(12.0 \%)$ in animals and lower prevalence of E. coli $\mathrm{O} 26$ (8.0\%) and $\mathrm{O} 113$ (2.0\%). E. coli O26 was present in $9.52 \%$ of the knives. The presence of E. coli non-O157 sorbitol negative was an unexpected fact due to the method of isolation. All E. coli O157: H7 isolates were sensitive to tetracycline, cefepime, cefoxitin, ciprofloxacin and sulphazotrim, and $78.85 \%$ of them were resistant to cephalothin and $34.61 \%$ to ampicillin. All E. coli $\mathrm{O} 26$ were sensitive to cefepime, cefoxitin and sulphazotrim, and $88.23 \%$ were resistant to tetracycline and cephalothin and $82.35 \%$ to ampicillin. The antimicrobial multiresistance was observed in both serotypes. It should be, therefore, a criteria for using antimicrobial in treatments to avoid become a public health concern.
\end{abstract}

KEYWORDS: Escherichia coli; cattle slaughterhouse; antimicrobial.

\footnotetext{
'Faculdade de Ciências Agrárias e Veterinárias; Universidade Estadual Paulista “Júlio de Mesquita Filho” (UNESP) - Jaboticabal (SP), Brasil. ${ }^{2}$ Faculté de Médicine Vétérinaire; Université de Montréal - Saint-Hyacinthe (QC), Canadá.

*Autor correspondente: natinespolo@yahoo.com.br

Recebido em: 20/12/2012. Aceito em: 03/07/2014
} 


\section{INTRODUÇÃO}

Entre os grupos das E. coli, as enterohemorrágicas (EHEC) são consideradas as mais patogênicas para os seres humanos, e podem ser transmitidas das fezes do bovino para a água, os vegetais ou os alimentos de origem animal, como o leite e seus derivados, assim como as carnes e seus derivados. As EHEC presentes nos bovinos podem ser transmitidas das fezes do animal para a carcaça no abatedouro, tornando-se a principal via de transmissão para os humanos que ingerem a carne mal cozida (Nataro; Kaper, 1998; Meng et al., 2007; ShaH et al., 2010).

Apesar de a E. coli O157:H7 ser a mais conhecida deste grupo, cepas de diferentes sorotipos também possuem alto potencial patogênico. Patógenos pertencentes ao sorogrupo das E. coli não-O157 são considerados emergentes e um problema para a saúde pública, uma vez que eles também têm sido associados a doenças severas em seres humanos, como a Síndrome Hemolítica Urêmica (SHU), Colite Hemorrágica (CH) e outras doenças gastrointestinais (Buvens et al., 2012; SASAKI et al., 2012).

Entre os diversos sorotipos de $E$. coli náo-O157, encontram-se o O147, O141, O113, O116, O82, O75, O73, $\mathrm{O} 71, \mathrm{O} 53, \mathrm{O} 26, \mathrm{O} 23, \mathrm{O} 22, \mathrm{O} 7, \mathrm{O} 4$ e NT, isolados anteriormente em humanos, bovinos e alimentos de origem animal (Bettelheim, 1978; Constantiniu, 2002). Os sorotipos O22, O23, O26, O75, O113 e NT foram descritos em pacientes com SHU. Esses sorotipos e os sorotipos O82, O113 e O141 foram associados a casos de diarreia, colite hemorrágica, dor abdominal, colite ulcerativa ou púrpura trombocitopênica trombótica, e o O26, O55, O11, O126, O127 e O128, à gastroenterite infantil (BetTelheim, 1978; Constantiniu, 2002; Hussein, 2007).

Os sorotipos $\mathrm{O} 26$ e $\mathrm{O} 113$ são considerados patógenos emergentes, responsáveis por surtos de doença de origem alimentar em diversos países (MATHusa et al., 2010; JoRIs et al., 2011; Monaghan et al., 2011), sendo que o sorotipo predominantemente responsável por causar doenças severas nos humanos é o O26 (Buvens et al., 2012; SASAKI et al., 2012).

$\mathrm{O}$ aumento e a disseminação da resistência bacteriana têm sido documentadas como um problema de saúde pública mundialmente conhecido, causando preocupação em relação à eficácia nos tratamentos das doenças. A pressão da seleção de antibióticos é favorecida pela falta de informaçóes sobre como os animais contribuem para a resistência de cepas de E. coli que causam doença em humanos, já que os mesmos antibióticos são usados para tratar animais e humanos, e também são utilizados como promotores de crescimento na pecuária (Schroeder et al., 2002; Maynard et al., 2004).

$\mathrm{O}$ uso de antimicrobianos como agentes promotores de crescimento em animais de produção foi incriminado por modificar a microbiota intestinal dos animais pela criaçáo de uma pressão de seleção, favorecendo o desenvolvimento de cepas resistentes a antimicrobianos (Diarra et al., 2009).

A perda ou adesão de alguns genes pode ocorrer em algumas cepas de E. coli, que são conhecidas por ter uma boa capacidade de realizar transferência horizontal de genes para aumentar a diversidade genética (MANNA et al., 2010), incluindo o desenvolvimento da multirresistência a antimicrobianos (Schroeder et al., 2002).

A multirresistência pode se tornar um problema de saúde pública se os humanos se infectarem pela bactéria devido à ingestấo de carne contaminada, já que isolados resistentes a antimicrobianos presentes nos animais de produção podem entrar no fluxograma de produçáo do alimento e serem encontrados nos produtos de origem animal presentes nos mercados (Diarra et al, 2009).

A ocorrência e a suscetibilidade de E. coli $\mathrm{O} 157$ e nãoO157 a antimicrobianos têm sido estudadas (SCHROEDER et al., 2002; VAZ et al., 2004; Joris et al., 2011; Buvens et al., 2012; SASAKI et al., 2012), entretanto, há poucos relatos desses sorotipos em abatedouros bovinos, principalmente no Brasil.

Diante do exposto, o trabalho teve como objetivo verificar a ocorrência de E. coli O157:H7 e não-O157 em diversas etapas do abate bovino e avaliar o comportamento dessas bactérias frente à ação de antimicrobianos.

\section{MATERIAL E MÉTODOS}

\section{Coleta do material}

Foram colhidas em abatedouro bovino, localizado no estado de São Paulo, 349 amostras, sendo sete de água de abastecimento da indústria, 21 de superfície de mãos dos manipuladores, 21 de superfície de facas e 300 provenientes de 50 animais em seis pontos no fluxograma de abate: fezes e pele dos animais, superfície externa e interna das carcaças, água residuária da lavagem das carcaças e carne.

As amostras da água de abastecimento da indústria foram coletadas em sacos de polietileno estéreis contendo pastilhas de tiossulfato de sódio a 10\% (Whirl-pak, Nasco), em quantidade aproximada de $400 \mathrm{~mL}$, e o teor de cloro residual livre foi determinado na própria indústria, que atende a determinação do Ministério da Agricultura, Pecuária e Abastecimento (MAPA). A coleta das amostras foi realizada de acordo com o fluxograma de abate, e os animais escolhidos foram etiquetados numericamente no traseiro e no dianteiro, para obter amostras sempre do mesmo animal. Foram coletadas amostras de fezes no reto do animal, da pele e da musculatura interna e externa das carcaças por meio de suabes embebidos em água peptonada a $0,1 \%$, e da água de lavagem que escorre pelas faces internas e externas das meias carcaças. Amostras de carne foram coletadas 24 horas após a entrada da carcaça na câmara 
fria, no momento anterior à desossa. A colheita de material das facas e mãos também foi realizada por meio de suabes. Após a colheita, as amostras foram acondicionadas em caixa isotérmica contendo gelo reciclável e encaminhadas ao laboratório do Departamento de Medicina Veterinária Preventiva, da Universidade Estadual Paulista, campus de Jaboticabal, para a realização das análises.

\section{Metodologia de isolamento}

$\mathrm{O}$ isolamento foi realizado de acordo com a metodologia descrita por Apнa (2001) para E. coli O157:H7, utilizando o TSBm (Modified tryptone soya broth, Oxoid, England) adicionado de novobiocina $(20 \mathrm{mg} / \mathrm{L}$ - Novobiocin selective supplement, Oxoid, England) como caldo de enriquecimento e incubação a $37^{\circ} \mathrm{C}$, sendo numa primeira fase sob agitação por 6 horas e, em seguida, por 18 horas em repouso. Do ágar MacConkey Sorbitol (Oxoid, England) adicionado de $0,05 \mathrm{mg} / \mathrm{L}$ de cefixima e $2,5 \mathrm{mg} / \mathrm{L}$ de telurito de potássio (CT-SMAC, Invitrogen, USA), foram tomadas até cinco colônias sorbitol negativas e, uma vez caracterizadas como bastonetes Gram negativos, foram submetidas às provas de produção de indol, inoculação em ágar Tríplice Açúcar Ferro (TSI), Vermelho de Metila (VM), Voges-Proskauer (VP), aproveitamento de citrato (C), motilidade, fermentação do sorbitol e descarboxilação da lisina e ornitina (FADDIN, 1976).

\section{Caracterização molecular de $E$. coli}

A PCR foi realizada no laboratório referência da OIE (Organização Mundial de Saúde Animal) para E. coli (EcL), daUniversité de Montreal, no Canadá, para caracterização da $E$. coli O157:H7 e também das E. coli não-O157: O26, O55, O91, O103, O111, O113, O121 e O145, mesmo que esses sorogrupos sejam conhecidos por fermentarem o sorbitol (Tabela 1). O DNA foi extraído pelo método de fervura, de acordo com a metodologia utilizada pelo laboratório referência da OIE para E.coli, a partir de colônias isoladas em placas de Petri contendo ágar Sangue (Oxoid, England).

\section{Teste de suscetibilidade frente a antimicrobianos}

$O$ teste de sensibilidade a antimicrobianos foi realizado conforme o método de difusão em discos Kirb-Bauer em ágar Muller-Hinton (Merck) (NCCLS, 1990). Os antimicrobianos utilizados foram amicacina $(30 \mu \mathrm{g})$, amoxicilina/ácido clavulânico $(30 \mu \mathrm{g})$, ampicilina $(10 \mu \mathrm{g})$, aztreonam $(30 \mu \mathrm{g})$, cefalotina $(30 \mu \mathrm{g})$, cefepime $(30 \mu \mathrm{g})$, cefoxitina $(30 \mu \mathrm{g})$, ceftadizima $(30 \mu \mathrm{g})$, ceftriaxona $(30 \mu \mathrm{g})$, ciprofloxacina $(5 \mu \mathrm{g})$, cloranfenicol $(30 \mu \mathrm{g})$, gentamicina $(10 \mu \mathrm{g})$, piperacilina/tazobactam $(110 \mu \mathrm{g})$, sulfazotrim $(25 \mu \mathrm{g})$, tetraciclina $(30 \mu \mathrm{g})$ (Polisensidisc $15 \mathrm{DME}^{\circledR}$ série Gram-negativo).

\section{Análise Estatística}

Todos os dados foram digitados em planilhas de computador, utilizando o programa Microsoft Excel $^{\circledR}$. As planilhas geraram estatística descritiva, incluindo a ocorrência de E. coli e gráficos de resistência aos antimicrobianos.

\section{RESULTADOS E DISCUSSÃO}

\section{Ocorrência de Escherichia coli}

Dos 50 animais coletados, seis $(12,0 \%)$ apresentaram $E$. coli O157:H7; quatro (8,0\%), E. coli O26; e um $(2,0 \%)$, E. coli $\mathrm{O} 113$. Em dois $(9,52 \%)$ dos 21 suabes de faca, isolou-se a $E$. coli $\mathrm{O} 26$, fato inesperado, uma vez que, segundo SнAн et al. (2010), apenas aproximadamente $6 \%$ de isolados atípicos das E. coli não-O157 não fermentam o sorbitol. Em relação aos pontos coletados, verificou-se a presença da E. coli $\mathrm{O} 157: \mathrm{H} 7$ nas fezes de três $(6,0 \%)$ animais, na pele de um $(2,0 \%)$ e, concomitantemente, nas fezes e pele de dois $(4,0 \%)$. A E. coli $\mathrm{O} 26$ foi identificada na pele de três $(6,0 \%)$ animais, no músculo externo da carcaça de um $(2,0 \%)$, na água residuária da lavagem da carcaça de um $(2,0 \%)$ e em duas $(9,52 \%)$ suabes de facas.

Não houve a presença de bactérias na água de abastecimento da indústria, confirmando a eficiência do cloro em seu tratamento. Observa-se, pela presença de E. coli patogênicas em algumas etapas do abate, que há o risco de transmissão desses micro-organismos durante o processamento, o que confirma a possibilidade de tais bactérias chegarem à carne $\mathrm{e}$ serem ingeridas pelos consumidores. A presença da bactéria na faca dos manipuladores durante a evisceraçáo mostra que este objeto não está sendo esterilizado de maneira corret, conforme designa a circular № $175 / 2005$, do MAPA, que preconiza a esterilização das facas por 20 segundos a $82^{\circ} \mathrm{C}$, no mínimo, após cada operação, pois durante a evisceração pode ocorrer uma contaminação da carcaça mais extensa por conteúdo gastrointestinal (BrasiL, 2005). Elder et al. (2000) também indicaram que o processo de evisceraçáo é um ponto crítico de controle para a contaminação das carcaças, e estratégias de intervenção devem ser implementadas.

A ocorrência de $E$. coli $\mathrm{O} 157: \mathrm{H} 7$ neste estudo (12,0\%) foi maior do que a relatada por VAZ et al. (2004), em um estudo retrospectivo de E. coli em humanos no Brasil (6,67\%), e por Buvens et al. (2012), em um estudo sobre a a incidência e determinantes de virulência de STEC em casos de infecçôes na Bélgica (0,23\%). Já Kappeli et al. (2011) obtiveram STEC O157:H7 em 100\% das amostras provenientes de casos clínicos na Suíça.

Thomas et al. (2012), no intuito de rastrear diversos sorotipos de $E$. coli em etapas do abate bovino no Irã, verificaram prevalência de E. coli O157 de 18,9\% nas 
Tabela 1. Características dos primers utilizados na PCR.

\begin{tabular}{|c|c|c|c|c|c|c|}
\hline Sorotipo & Gene & Sequência $\left(5^{\prime} \rightarrow 3^{\prime}\right)$ & $\begin{array}{c}\text { PCR } \\
\text { amplicon } \\
\text { (pb) }\end{array}$ & Condições da PCR & $\begin{array}{l}\text { Concentração } \\
\text { do primer } \\
\text { (pmol) }\end{array}$ & Referência \\
\hline $\begin{array}{l}\text { E. coli } \\
0157\end{array}$ & $r f b \mathrm{E}_{0157}$ & $\begin{array}{l}\text { F: CTACAGGTGAAGGTGGAATGG } \\
\text { R: ATTCCTCTCTTTCCTCTGCGG }\end{array}$ & 327 & $\begin{array}{c}94^{\circ} \mathrm{C}, 5 \mathrm{~min} ; 24 \text { ciclos } \\
\text { de } 94^{\circ} \mathrm{C} \text { por } 30 \mathrm{~s}, 60^{\circ} \mathrm{C} \\
\text { por } 30 \mathrm{~s}, 72^{\circ} \mathrm{C} \text { por } 30 \mathrm{~s} ; \\
\text { extensão final de } 72^{\circ} \mathrm{C} \text {, } \\
5 \mathrm{~min}\end{array}$ & 10 & $\begin{array}{l}\text { WANG et al., } \\
2002\end{array}$ \\
\hline E. coli H7 & flic $_{\mathrm{H} 7}$ & $\begin{array}{l}\text { F: GCGCTGTCGAGTTCTATCGAGC } \\
\text { R: AACGGTGACTTATCGCCATTCC }\end{array}$ & 625 & $\begin{array}{c}94^{\circ} \mathrm{C}, 5 \mathrm{~min} ; 24 \text { ciclos } \\
\text { de } 94^{\circ} \mathrm{C} \text { por } 30 \mathrm{~s}, 60^{\circ} \mathrm{C} \\
\text { por } 30 \mathrm{~s}, 72^{\circ} \mathrm{C} \text { por } 30 \mathrm{~s} ; \\
\text { extensão final de } 72^{\circ} \mathrm{C} \text {, } \\
5 \mathrm{~min}\end{array}$ & 10 & $\begin{array}{l}\text { GANNON } \\
\text { et al., } 1997\end{array}$ \\
\hline $\begin{array}{l}\text { E. coli } \\
026\end{array}$ & $\begin{array}{l}\text { wzx- } \\
\text { wzy } \\
026\end{array}$ & $\begin{array}{l}\text { F: AAATTAGAAGCGCGTTCATC } \\
\text { R: CCCAGCAAGCCAATTATGACT }\end{array}$ & 596 & $\begin{array}{c}94^{\circ} \mathrm{C}, 5 \mathrm{~min} ; 24 \text { ciclos } \\
\text { de } 94^{\circ} \mathrm{C} \text { por } 30 \mathrm{~s}, 55^{\circ} \mathrm{C} \\
\text { por } 30 \mathrm{~s}, 72^{\circ} \mathrm{C} \text { por } 30 \mathrm{~s} ; \\
\text { extensão final de } 72^{\circ} \mathrm{C} \text {, } \\
5 \mathrm{~min}\end{array}$ & 10 & $\begin{array}{l}\text { DuRso et al., } \\
\quad 2005\end{array}$ \\
\hline $\begin{array}{l}\text { E. coli } \\
055\end{array}$ & $\begin{array}{c}\text { wbgN } \\
055\end{array}$ & $\begin{array}{l}\text { F: TGTAATTCGATGCACCAATTCAG } \\
\text { R: CGCTTCGACGTTCGATACATAA }\end{array}$ & 70 & $\begin{array}{c}94^{\circ} \mathrm{C}, 5 \mathrm{~min} ; 24 \text { ciclos } \\
\text { de } 94^{\circ} \mathrm{C} \text { por } 30 \mathrm{~s}, 55^{\circ} \mathrm{C} \\
\text { por } 30 \mathrm{~s}, 72^{\circ} \mathrm{C} \text { por } 30 \mathrm{~s} \text {; } \\
\text { extensão final de } 72^{\circ} \mathrm{C} \text {, } \\
5 \mathrm{~min}\end{array}$ & 10 & $\begin{array}{l}\text { PERELLE } \\
\text { et al., } 2004\end{array}$ \\
\hline $\begin{array}{l}\text { E. coli } \\
091\end{array}$ & $\begin{array}{l}\text { wzy } \\
091\end{array}$ & $\begin{array}{c}\text { F: CGATTTTCTGGAATGCTTGATG } \\
\text { R: CAATACATAGTTTGATTTGTGTTTAAAGTTTAAT }\end{array}$ & 105 & $\begin{array}{c}94^{\circ} \mathrm{C}, 5 \mathrm{~min} ; 24 \text { ciclos } \\
\text { de } 94^{\circ} \mathrm{C} \text { por } 30 \mathrm{~s}, 55^{\circ} \mathrm{C} \\
\text { por } 30 \mathrm{~s}, 72^{\circ} \mathrm{C} \text { por } 30 \mathrm{~s} \text {; } \\
\text { extensão final de } 72^{\circ} \mathrm{C} \text {, } \\
5 \mathrm{~min}\end{array}$ & 10 & $\begin{array}{l}\text { PERELLE } \\
\text { et al., } 2004\end{array}$ \\
\hline $\begin{array}{l}\text { E. coli } \\
0103\end{array}$ & $\begin{array}{c}\text { wzx } \\
0103\end{array}$ & $\begin{array}{l}\text { F: TTGGAGCGTTAACTGGACCT } \\
\text { R: GCTCCCGAGCACGTATAAG }\end{array}$ & $\begin{array}{l}321- \\
280\end{array}$ & $\begin{array}{c}94^{\circ} \mathrm{C}, 5 \mathrm{~min} ; 24 \text { ciclos } \\
\text { de } 94^{\circ} \mathrm{C} \text { por } 30 \mathrm{~s}, 55^{\circ} \mathrm{C} \\
\text { por } 30 \mathrm{~s}, 72^{\circ} \mathrm{C} \text { por } 30 \mathrm{~s} ; \\
\text { extensão final de } 72^{\circ} \mathrm{C} \text {, } \\
5 \mathrm{~min}\end{array}$ & 10 & $\begin{array}{l}\text { FRATAMICO } \\
\text { et al., } 2005\end{array}$ \\
\hline $\begin{array}{l}\text { E. coli } \\
0111\end{array}$ & 0111 & $\begin{array}{l}\text { F: TAGAGAAATTATCAAGTTAGTTCC } \\
\text { R: ATAGTTATGAACATCTTGTTTAGC }\end{array}$ & 406 & $\begin{array}{c}94^{\circ} \mathrm{C}, 5 \mathrm{~min} ; 24 \text { ciclos } \\
\text { de } 94^{\circ} \mathrm{C} \text { por } 30 \mathrm{~s}, 60^{\circ} \mathrm{C} \\
\text { por } 30 \mathrm{~s}, 72^{\circ} \mathrm{C} \text { por } 30 \mathrm{~s} ; \\
\text { extensão final de } 72^{\circ} \mathrm{C} \text {, } \\
5 \mathrm{~min}\end{array}$ & 10 & $\begin{array}{c}\text { PATON \& } \\
\text { PATON, } \\
1998\end{array}$ \\
\hline $\begin{array}{l}\text { E. coli } \\
0113\end{array}$ & 0113 & $\begin{array}{l}\text { F: AGCGTITCTGACATATGGAGTG } \\
\text { R: GTGTTAGTATCAAAAGAGGCTCC }\end{array}$ & 593 & $\begin{array}{c}94^{\circ} \mathrm{C}, 5 \mathrm{~min} ; 24 \text { ciclos } \\
\text { de } 94^{\circ} \mathrm{C} \text { por } 30 \mathrm{~s}, 60^{\circ} \mathrm{C} \\
\text { por } 30 \mathrm{~s}, 7^{\circ} \mathrm{C} \text { por } 30 \mathrm{~s} ; \\
\text { extensão final de } 72^{\circ} \mathrm{C} \text {, } \\
5 \mathrm{~min}\end{array}$ & 10 & $\begin{array}{l}\text { PATON et al., } \\
1999\end{array}$ \\
\hline $\begin{array}{l}\text { E. coli } \\
0121\end{array}$ & $\begin{array}{c}\text { wzx } \\
0121\end{array}$ & $\begin{array}{l}\text { F: GTAGCGAAAGGTTAGACTGG } \\
\text { R: ATGGGAAAGCTGATACTGC }\end{array}$ & 651 & $\begin{array}{l}94^{\circ} \mathrm{C}, 5 \mathrm{~min} ; 24 \text { ciclos } \\
\text { de } 94^{\circ} \mathrm{C} \text { por } 30 \mathrm{~s}, 60^{\circ} \mathrm{C} \\
\text { por } 30 \mathrm{~s}, 72^{\circ} \mathrm{C} \text { por } 30 \mathrm{~s} ; \\
\text { extensão final de } 72^{\circ} \mathrm{C} \text {, } \\
5 \mathrm{~min}\end{array}$ & 10 & $\begin{array}{l}\text { MONDAY } \\
\text { et al., } 2007\end{array}$ \\
\hline $\begin{array}{l}\text { E. coli } \\
0145\end{array}$ & $\begin{array}{l}\text { wzx } 1 \\
0145\end{array}$ & $\begin{array}{l}\text { F: ACTGGGATTGGACGTGGATA } \\
\text { R: AGGCAAGCTTTGGAAATGAA }\end{array}$ & 222 & $\begin{array}{c}94^{\circ} \mathrm{C}, 5 \mathrm{~min} ; 24 \text { ciclos } \\
\text { de } 94^{\circ} \mathrm{C} \text { por } 30 \mathrm{~s}, 55^{\circ} \mathrm{C} \\
\text { por } 30 \mathrm{~s}, 72^{\circ} \mathrm{C} \text { por } 30 \mathrm{~s} ; \\
\text { extensão final de } 72^{\circ} \mathrm{C} \text {, } \\
5 \mathrm{~min}\end{array}$ & 10 & $\begin{array}{l}\text { FRATAMICO } \\
\text { et al., } 2009\end{array}$ \\
\hline
\end{tabular}


amostras de pele, de $2,7 \%$ nas de fezes, de $0,7 \%$ nas carcaças pré-evisceradas e de $0,7 \%$ nas carcaças após a lavagem. Em relação a este estudo, as porcentagens citadas foram maiores para as amostras de pele $(2,0 \%)$ e menores para as de fezes $(6,0 \%)$. Os autores também identificaram o sorotipo $\mathrm{O} 26 \mathrm{em} 0,2 \%$ das amostras de pele, $1,5 \%$ das de fezes e em nenhuma carcaça, diferenciando-se deste estudo, que mostrou a presença da bactéria em $6,0 \%$ das amostras de pele, em nenhuma amostra de fezes e 2,0\% das amostras de músculo externo da carcaça.

PADDOCK et al. (2012), verificando a aplicabilidade da PCR multiplex para detectar $E$. coli náo-O157 e O157 em bovinos, identificaram a E. coli $\mathrm{O} 157 \mathrm{em} 49,0 \%$ e O26 em 82,0\% das amostras, valores maiores que os obtidos neste trabalho, de $12,0 \%$ e $8,0 \%$. Já Buvens et al. (2012), ao estudarem STEC em casos de infecçôes na Bélgica, relataram menor ocorrência de $E$. coli $\mathrm{O} 26(0,14 \%)$ em relaçáo a este estudo $(8,0 \%)$.

\section{Suscetibilidade a antimicrobianos}

Todos os 52 isolados de E. coli $\mathrm{O} 157: \mathrm{H} 7$ provenientes dos seis $(12,0 \%)$ animais foram sensíveis à tetraciclina, cefepime, cefoxitina, ciprofloxacina e sulfazotrim. A sensibilidade também foi relatada em $98,08 \%$ (51) dos isolados ao cloranfenicol, 94,23\% (49) à amoxicilina/ácido clavulânico, 88,46\% (46) à ceftriaxona e ao aztreonam, $86,54 \%$ (45) à ceftadizima e à gentamicina, 84,61\% (44) à piperacilina/tazobactam, 71,15\% (37) à amicacina, 51,92\% (27) à ampicilina e 15,38\% (8) à cefalotina. A resistência foi verificada em $78,85 \%$ (41) das culturas para a cefalotina, 34,61\% (18) para ampicilina, 7,70\% (4) para aztreonam e ceftadizima, $3,84 \%$ (2) para amicacina e piperacilina/tazobactam e 1,92\% (1) para gentamicina.
A multirresistência a antimicrobianos do sorotipo O157:H7 foi verificada em $46,15 \%$ (24) dos isolados, sendo $38,46 \%$ (20) resistentes a dois; $5,77 \%$ (3), a três; e $1,92 \%$ (1), a seis antibimicrobianos. A distribuição entre os 24 isolados foi de $70,83 \%$ (17) para ampicilina e cefalotina; 8,33\% (2) para aztreonam e cefalotina; $4,17 \%$ (1) para amicacina e cefalotina, assim como para ceftadizima, piperacilina/tazobactam e cefalotina, para ceftadizima, amicacina e cefalotina, para aztreonam, ceftadizima e cefalotina, e também para aztreonam, ceftadizima, piperacilina/tazobactam, ampicilina, gentamicina e cefalotina (Fig. 1).

Corroborando com este estudo, Schroeder et al. (2002) também encontraram E. coli O157:H7 em bovinos suscetíveis à cefoxitina, ciprofloxacina e ceftriaxona, porém, diferentemente deste estudo, no que se refere à tetraciclina, frente à qual $100 \%$ das culturas foram sensíveis. Os autores também relataram multirresistência a dois, três e seis antimicrobianos. Baixa porcentagem de resistência à ampicilina $(5,4 \%)$ e à gentamicina $(1,92 \%)$, e maior multirresistência $(75,0 \%)$ a dois, três, quatro, seis e oito antimicrobianos, também foram encontradas em gado de corte no Japáo (SASAKI et al., 2012).

Diferentemente deste estudo, KAPPELI et al. (2011) verificaram que 4,5\% dos isolados de STEC O157 provenientes de casos clínicos na Suíça foram resistentes à tetraciclina. Porém, assim como neste estudo, encontraram 100\% de sensibilidade para ciprofloxacina, cefepime e cefoxitina.

Todos os 17 isolados de E. coli $\mathrm{O} 26$ provenientes dos quatro $(8,0)$ animais e de dois $(9,52 \%)$ suabes de facas mostraram-se sensíveis à cefoxitina, cefepime e sulfazotrim; 82,35\% (14), à ciprofloxacina e cloranfenicol; $47,06 \%$ (8), ao aztreonam, amicacina e gentamicina; $35,29 \%$ (6), à piperacilina/tazobactam e

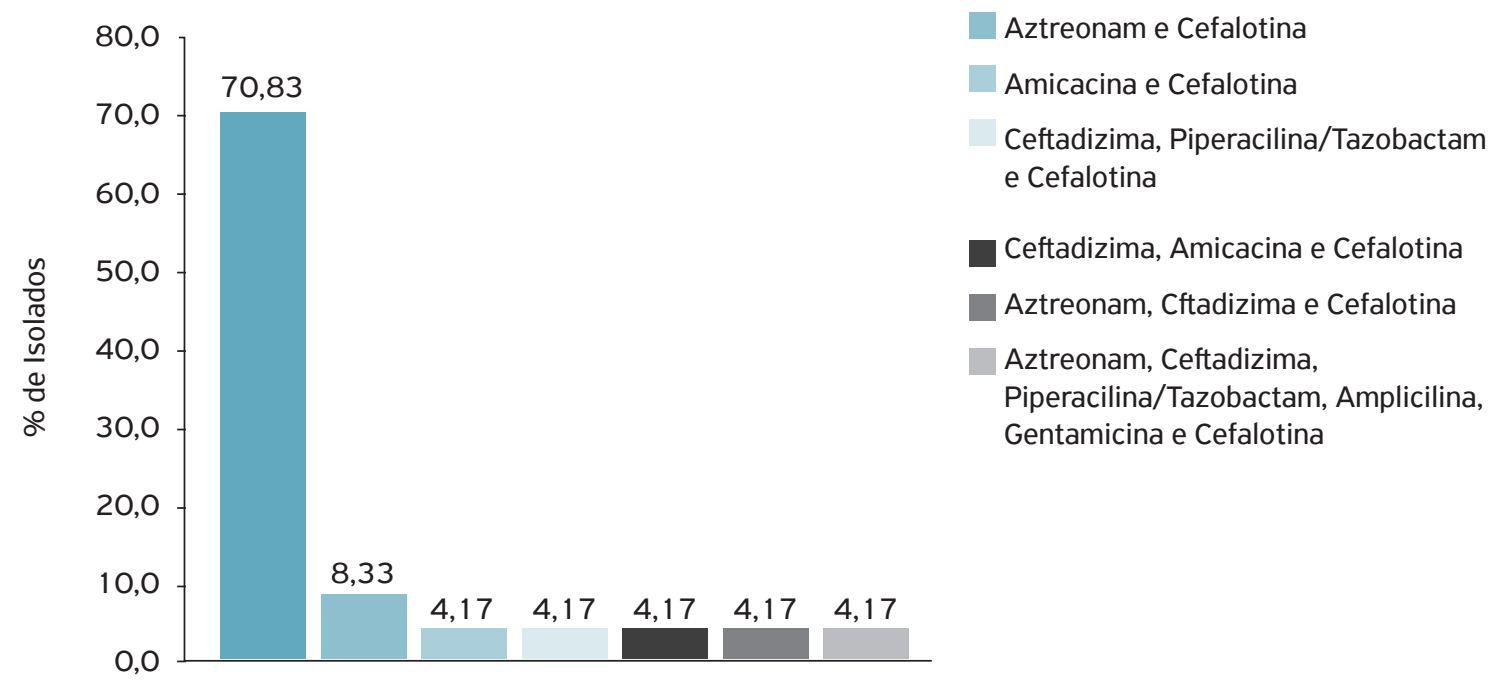

Figura 1. Multirresistência a antimicrobianos de $E$. coli 0157:H7. 
ceftriaxona; 23,53\% (4), à ceftadizima; 11,76\% (2), à amoxicilina/ácido clavulânico; e 5,88\% (1) à tetraciclina. A resistência foi verificada em $88,23 \%$ (15) dos isolados para tetraciclina e cefalotina, $82,35 \%$ (14) para ampicilina, $17,65 \%$ (3) para aztreonam, ceftadizima, piperacilina/tazobactam e amicacina, e 11,76\% (2) para gentamicina e amoxicilina/ácido clavulânico (Fig. 2).

A multirresistência aos antimicrobianos foi observada em $94,12 \%$ (16) dos isolados, sendo resistentes $11,76 \%$ (2) a dois, $29,41 \%$ (5) a três, $35,29 \%$ (6) a quatro, $11,76 \%$ (2) a cinco e $5,88 \%$ (1) a seis antibióticos. A distribuição entre os 16 isolados foi de $25 \%$ (4) para tetraciclina, ampicilina e cefalotina; $12,5 \%$ (2), para tetraciclina, amicacina, ampicilina e cefalotina; 6,25\% (1), para tetraciclina e cefalotina; 6,25\% (1), para ampicilina e cefalotina; 6,25\% (1), para tetraciclina, ampicilina e amoxicilina/ácido clavulânico; 6,25\% (1), para aztreonam, ceftadizima, tetraciclina e cefalotina; $6,25 \%$ (1), para tetraciclina, ampicilina, gentamicina e amoxicilina/ácido clavulânico; 6,25\% (1), para piperacilina/tazobactam, tetraciclina, ampicilina e cefalotina; $6,25 \%$ (1), para aztreonam, tetraciclina, ampicilina e cefalotina; 6,25\% (1), para piperacilina/tazobactam, tetraciclina, ampicilina, gentamicina e cefalotina; 6,25\% (1), para aztreonam, ceftadizima, tetraciclina, ampicilina e cefalotina; 6,25\% (1), para ceftadizima, piperacilina/tazobactam, tetraciclina, amicacina, ampicilina e cefalotina (Fig. 3).

$\mathrm{O}$ único isolado pertencente ao sorotipo $\mathrm{O} 113$ mostrou-se sensível à maioria dos antibimicrobianos testados, exceto para a ampicilina e cefalotina, às quais foi resistente.
Mora et al. (2005), analisando a resistência antimicrobiana de cepas de STEC O157:H7 e não-O157 isoladas de humanos, bovinos, ovelhas e alimentos na Espanha, verificaram porcentagem maior (98\%) de multirresistência entre as STEC O157:H7 em relação a este estudo (46,15\%), e os perfis de multirresistência frequentemente encontrados são diferentes, como sulfisoxazole, tetraciclina e estreptomicina.

SASAKI et al. (2012), ao estudarem a resistência a antimicrobianos em STEC O157 e O26 isoladas de gado de corte no Japáo, relataram 36,4\% das cepas de E. coli O26 resistentes à ampicilina, nenhuma à gentamicina e 18,2\% delas ao cloranfenicol, diferentemente deste estudo, que encontrou porcentagens maiores de $82,35 \%$ e $11,76 \%$ para ampicilina e gentamicina, respectivamente, e nenhuma cepa resistente ao cloranfenicol. Os autores verificaram multirresistência a dois, três, sete e oito antimicrobianos em $100 \%$ das cepas, porcentagem semelhante a este estudo, que foi de $94,12 \%$.

Buvens et al. (2012), em um estudo sobre a resistência de STEC O157 e O26 em casos de infecção em humanos na Bélgica, encontraram, para a $\mathrm{O} 157,32,4 \%$ de resistência para a tetraciclina, $23,5 \%$ para ampicilina e 2,9\% para cloranfenicol, porcentagens maiores para tetraciclina e cloranfenicol, e menor para a ampicilina em relação a este estudo. Os autores ainda relataram porcentagens de resistência menores de $E$. coli não-O157 em relação à ampicilina $(27,1 \%)$,

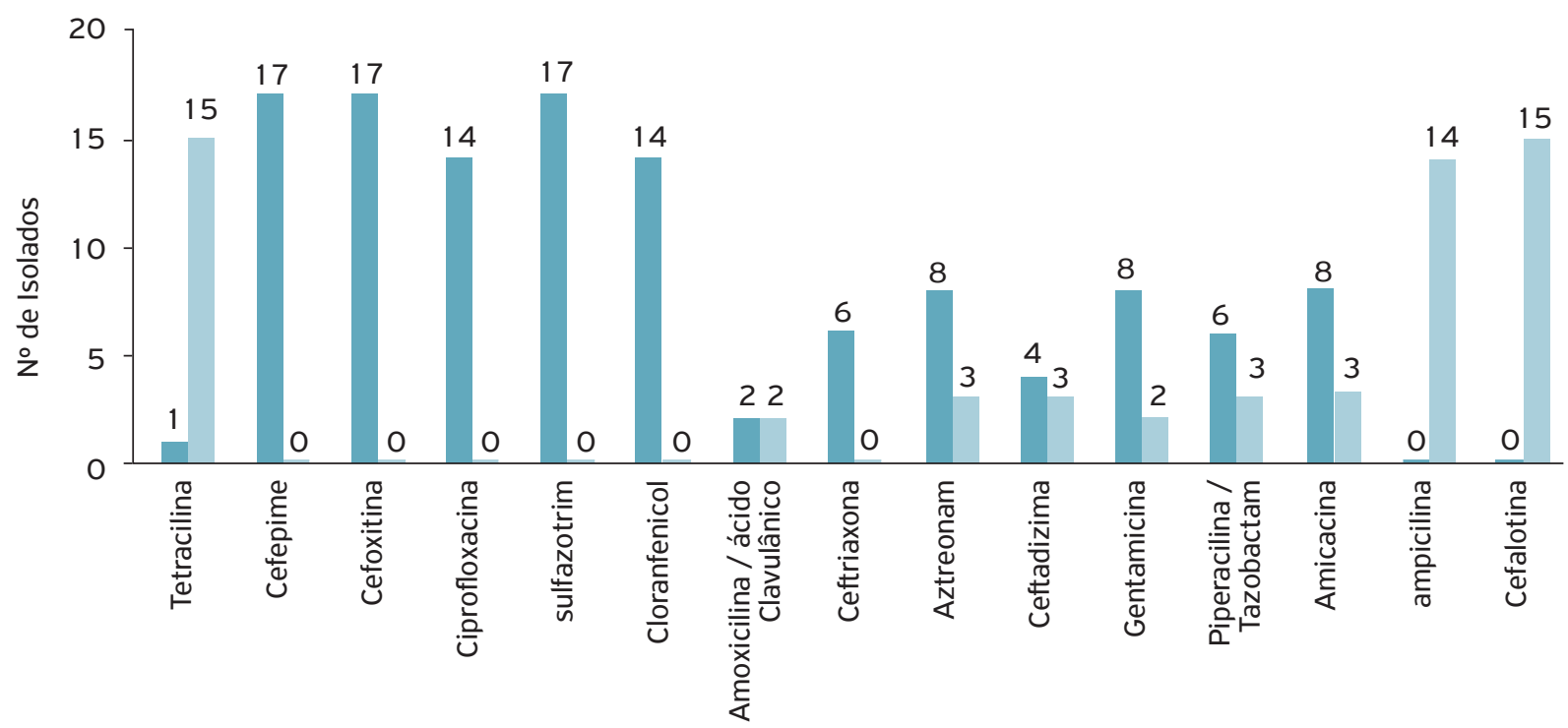

№ de Isolados Sensíveis

No de Isolados Resistentes 


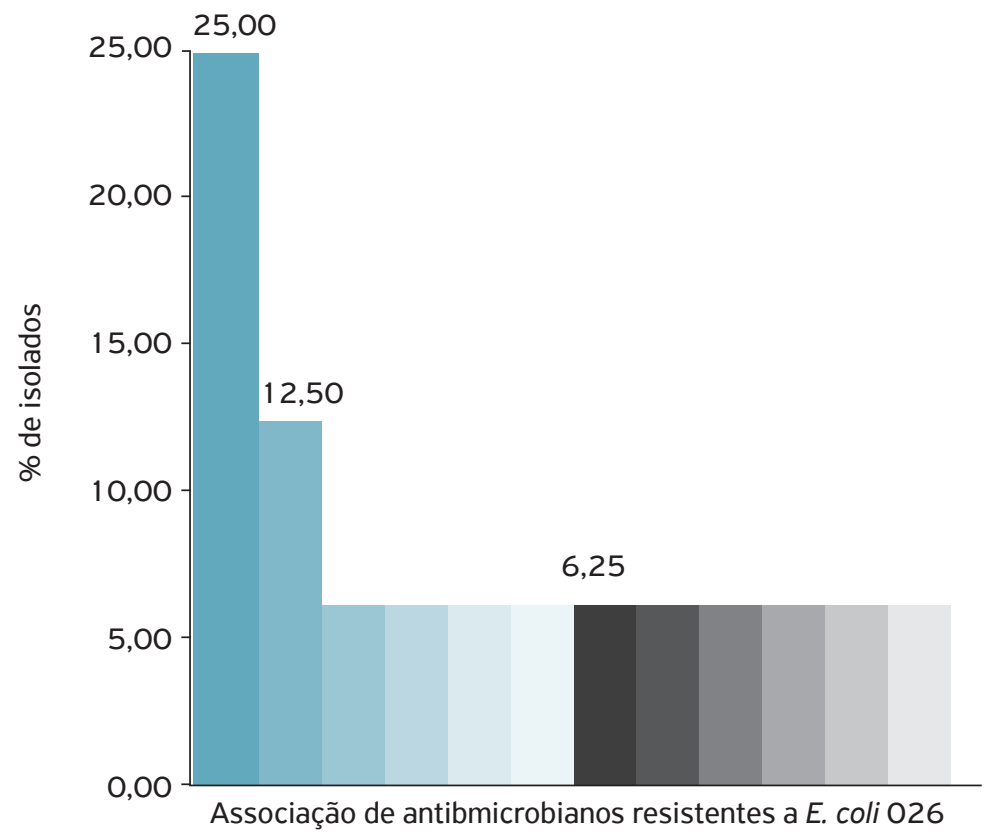

Tetraciclina, Ampicilina e Cefalotina

Tetraciclina, Amicacina, Ampicilina e cefalotina

Tetraciclina e Cefalotina

Ampicilina e Cefalotim

Tetraciclina, Ampicilina e Amoxicilina / Ácido Clavulânico

Aztreonam, Ceftadizima, letraciclina e Cefalotina

letraciclina, Ampicilina, Gentamicina e Amoxicilina / Ácido Clavulânico

Piperacilina / lazobactam, letraciclina, ampicilina e Cefalotina

Aztreonam, letaciclina, Ampicilina e Cefalotina

Piperacilina / lazobactam, letraciclina, Ampicilina, Gentamicina e Cefalotina

Azteonam, Fectadizima, letraciclina, Ampicilina, Gentamicina e Cefalotina

Ceftadizima, Piperacilina / lazobactam, letraciclina, Amicacuba, Ampicilina e Cefalotina

Figura 3. Perfil de multirresistência a antimicrobiano de E. coli 026.

tetraciclina (26,2\%), amoxicilina/ácido clavulânico (2,8\%), piperacilina/tazobactam $(1,9 \%)$, ceftadizima $(1,9 \%)$, gentamicina $(1,9 \%)$ e aztreonam $(0,9 \%)$ quando comparadas a E. coli $\mathrm{O} 26$ encontrada neste trabalho, que apresentou resistência, respectivamente, de 82,3\%, 88,23\%, 11,76\%, $17,65 \%, 17,65 \%, 11,76 \%$ e $17,65 \%$.

Buvens et al. (2012) verificaram alta sensibilidade da E. coli O157:H7 para piperacilina/tazobactam, ceftadizima, aztreonam, amicacina e gentamicina, e da O26 para ceftriaxona, cefepime, ciprofloxacina e amicacina, resultados similares aos deste estudo, exceto para a amicacina, cuja resistência foi de 17,65\%.

Entretanto, VAz et al. (2004) verificaram cepas pertencentes a E. coli $\mathrm{O} 157: \mathrm{H} 7$ e $\mathrm{O} 26$ isoladas de pacientes no Brasil, não multirresistentes a antimicrobianos.

A resistência a múltiplos antimicrobianos em STEC pode resultar da distribuição de elementos genéticos, como plasmídeos, transposons e íntegrons, que conferem resistência a vários antibióticos. Porém, outros estudos são necessários para definir os mecanismos e diminuir o desenvolvimento da resistência (Mora et al., 2005). A multirresistência a antimicrobianos também pode ser resultado da passagem horizontal de genes por mecanismos de transferência adotados pela bactéria (Schroeder et al., 2002) e se tornar um problema de saúde pública se os humanos se infectarem devido à ingestáo de carne contaminada.

Portanto, assim como Thomas et al. (2012), em um estudo sobre E. coli produtoras de verotoxina (VTEC) O157,
O26, $\mathrm{O} 103$ e $\mathrm{O} 145$ em gado iraniano, verifica-se que a E. coli O157:H7 foi a mais prevalente no matadouro-frigorífico. Porém, as não-O157, como a $\mathrm{O} 26$ e $\mathrm{O} 113$, que são potencialmente patogênicas, estão começando a emergir no processo de abate bovino no país. É importante revisar as medidas de prevenção dentro do frigorífico, a fim de evitar que elas cheguem à carne e prejudiquem a saúde do consumidor. Com isso, em concordância com VAz et al. (2004), nota-se que é ainda mais importante a implementação de um sistema de vigilância para pessoas com diarreia sanguinolenta e SHU no Brasil, a fim de contribuir com a estimativa real da associação de cepas de E. coli O157:H7 e não-O157 com infecçôes humanas. Apesar de grande parte dos isolados deste estudo serem suscetíveis à maioria dos antimicrobianos testados, eles devem ser usados com critério para evitar a multirresistência em tratamentos futuros, visto que muitos antibimicrobianos são usados tanto na medicina veterinária quanto na humana.

\section{AGRADECIMENTOS}

Ao CNPQ, pela bolsa concedida; à Capes pela bolsa PDSE no exterior, processo número 9482-11-3, e à indústria onde o trabalho foi realizado. 


\section{REFERÊNCIAS}

APHA. AMERICAN PUBLIC HEALTH ASSOCIATION. Committee on Microbiological for foods. Compendium of methods for the microbiological examination of foods. 4 ed. Washington: American Public Health Association. 2001. 676p.

BUVENS, G.; GHELDRE, Y.; DEDISTE, A.; MOREAU, A.; MASCART, G.; SIMON, A.; SCHEUTZ, D.F.; LAUWERS, S.; PIÉRARD, D. Incidence and virulence determinants of verocytotoxin-producing Escherichia coli infection in the Brussels - capital region Belgium in 20082010. Journal of Clinical Microbiology, Washington, v.50, n.4, p.1336-1345, 2012.

DURSO, L.M.; BONO, J.L.; KEEN, J.E. Molecular serotyping of Escherichia coli $026: \mathrm{H} 1$ 1. Applied and Environmental Microbiology, Washington, v.71, n.8, p.4941-4944, 2005

ELDER, R.O.; KEEN, J.E.; SIRAGUSA, G.R.; BARKOCY-GALLAGHER, G.A.; KOOHMARAIE, M.; LAEGREID, W.W. Correlation of enterohemorrhagic Escherichia coli 0157 prevalence in feces, hides, and carcass of beef cattle during processing. Applied Biological Sciences, Boston, v.97, n.7, p.2999-3003, 2000.

FADDIN, J.F. Biochemical tests for identification of medical bacteria. Baltimore: The Williams e Wikins Co. 1976. 312p.

FRATAMICO, P.M.; DEBROY, C.; STROBAUGH JR., T.P.; CHEN, C. DNA sequence of the Escherichia coli 01030 antigen gene cluster and detection of enterohemorrhagic E. coli 0103 by PCR amplification of the wzx and wzy genes. Canadian Journal of Microbiology, Ottawa, v.51, n.6, p.515-522, 2005.

FRATAMICO, P.M.; DEBROY, C.; MIYAMOTO, T.; LIU, Y. PCR Detection of Enterohemorrhagic Escherichia coli 0145 in Food by Targeting Genes in the E. coli 0145 O-Antigen Gene Cluster and the Shiga Toxin 1 and Shiga Toxin 2 Genes. Foodborne Pathogens and Disease, New Rochelle, v.6, n.5, p.605-611, 2009.

GANNON, V.P.G.; D'SOUZA, S.; GRAHAM, T.; KING, R.K. ; RAHN, K. READ, S. Use of the flagellar $\mathrm{H} 7$ gene as a target in multiplex PCR assays and improved specificity in identification of enterohaemorrhagic Escherichia coli strains. Journal of Clinical Microbiology, Washington, v.35, n.3, p.656-662, 1997.

JORIS, M.A.; PIERARD, D.; ZUTTER, L. Occurrence and virulence patterns of $E$. coli 026, 0103,011 and 0145 in slaughter cattle. Veterinary Microbiology, Amsterdam, v.151, p.418-421, 2011.

KAPPELI, U.; HACHLER, H.; GIEZENDANNER, N.; CHEASTY, T,; STEPHAN, R. Shiga toxin producing Escherichia coli 0157 associated with human infections in Switzerland, 20002009. Epidemiology and Infection, Nova York, v.139, p. 1097-1104, 2011.

MAYNARD, C.; BEKAL, S; SANSCHAGRIN, F.; LEVESQUE, R.C.; BROUSSEAU, R.; MASSON, L.; LARIVIERE, S.; HAREL, J. Heterogeneity among virulence and antimicrobial rsistance gene profiles of extraintestinalEscherichia coli isolates of animal and human origin. Journal of Clinical Microbiology, Washington, v.42, n. 12, p.5444-5452, 2004
MONDAY, S.R.; BEISAW, A.; FENG, P.C.H. Identification of Shiga toxigenic Escherichia coli seropathotypes A and B by multiplex PCR. Molecular and Cellular Probes, London, v.21, n.4, p.308-311, 2007.

MORA, A.; BLANCO, J.E.; BLANCO, M.; ALONSO, M.P.; DHABI, G.; ECHEITA, A.; GONZÁLEZ, E.A.; BERNÁRDEZ, M.I.; BLANCO, J. Antimicrobial resistance of shiga toxin (verotoxin)-producing Escherihcia coli 0157:H7 and non-0157 strains isolated from humans, cattle, sheep and food in Spain. Research in Microbiology, Amsterdam, v.156, n.7, p.793-806, 2005.

MENG, J.; DOYLE, M.P.; ZHAO, T.; ZHAO, S. Enterohemorrhagic Escherichia coli. In: DOYLE, M.P.; BEUCHAT, L.R. Food Microbiology: fundamentals and frontiers. Washington: ASM Press, 2007. p.249-269.

MINISTÉRIO DA AGRICULTURA PECUÁRIA E ABASTECIMENTO. Secretaria de defesa Agrapecuária-SDA. Departamento de Inspeção de Produtos de origem Animal - DIPOA. Coordenação Geral de Programas Especiais - CGPE (Circular № 175/2005/CGPE/DIPOA, de 16 de maio de 2005). Procedimentos de Verificação dos Programas de Autocontrole. Brasília: Ministério da Agricultura, 2005. 39 p.

NATARO, J.P.; KAPER, J.B. Diarrheagenic Escherichia coli. Clinical Microbiology Reviews, Washington, v.1 1, n.1, p.142-201, 1998.

NATIONAL COMMITTEE FOR CLINICAL LABORATORY STUDIES. Performance standards for antimicrobial disk susceptibility tests. 4. ed. Vilanova: NCCLS, 1990. (NCCLS document M2-A4).

PADDOCK, Z.; SHI, X.; BAI, J.; NAGARAJA, T.G. Applicability of a multiplex PCR to detect 026, 045, 0103, 0111,0121 , 0145 and 0157 serogroups of Escherichia coli in cattle feces. Veterinary Microbiology, Amsterdam, v.156, p.381-388, 2012.

PATON, A.W.; PATON, J.C. Detection and characterization of shiga toxigenic Escherichia coli by using multiplex PCR assays for stx 1, stx2, eaeA, Enterohemorragic E. coli hlyA, rfb 0111 and rfbo 157. Journal of Clinical Microbiology, Washington, v.36, n.2, p.598-602, 1998.

PATON, A.W.; WOODROW, M.C.; DOYLE, R.; LANSER, J.A.; PATON, J.C. Molecular characterization of a shiga toxigenic Escherichia coli 0113:H2 1 strain lacking eae responsible for a cluster of cases of hemolytic-uremic syndrome. Journal of Clinical Microbilogy, Washington, v.37, n.10, p.3357-3361, 1999.

PERELLE, S.; DILASSER, F.; GROUT, J.; FACH, P. Detection by 5'-nuclease PCR of shiga-toxin producing Escherichia coli 026 , 055, 091, 0103, $0111,0113,0145$ and 0157:H7, associated with the world's most frequent clinical cases. Molecular and Cellular Probes, v.18, p.185-192, 2004.

SASAKI, Y.; USUI, M.; MURAKAMI, M.; HARUNA, M.; KOJIMA, A.; ASAI, T.; YAMADA,Y. Antimicrobial resistance in shiga toxinproducing Escherichia coli 0157 and 026 isolates from beef cattle. Japanese Journal of Infectious Diseases, Shinjuku-ku, v.65, n.2, p.117-121, 2012. 
SCHROEDER, C.M.; ZHAO, C.; DEBROY, C.; TORCOLINI, J.; ZHAO, S.; WHITE, D.G.; WAGNER, D.D.; MCDEMOTT, P.F.; WLAKER, R.D.; MENG $\mathrm{J}$. Antimicrobial resistance of Escherichia coli 0157 isolated from humans, cattle, swine and food. Applied and Environmental Microbiology, Washington, v.68, n.2, p.576-581, 2002.

SHAH, D.H.; SHRINGI, S.; BESSER, T.E.; CALL, D.R. Escherichia. In: LIU, D. (Ed.). Molecular detection of foodborne pathogens. Boca Raton: CRC Press, 2010. p.369-389.

THOMAS, K.M.; MCCAM, M.S.; COLLERY, M.M.; LOGAN, A.; WHYTE, P.; McDOWELL, D.A.; DUFFY, G. Tracking verocytotoxigenic Escherichia coli 0157, 026, 0111,0103 and 0145 in Irish cattle. International Journal of Food Microbiology, Amsterdam, v. 153, p.288-296, 2012.
VAZ, T.M.I.; IRINO, K.; KATO, M.A.M.F.; DIAS, A.M.G.; GOMES, T.A.T.; MEDEIROS, M.I.C.; ROCHA, M.M.M.; GUTH, B.E.C. Virulence properties and characteristics of shiga toxin-producing Escherichia coli in São Paulo, Brazil, from 1976 through 1999. Journal of Clinical Microbiology, Washington, v.42, n.2, p.903-905, 2004.

WANG, G.; CLARK, C.G.; RODGERS, F.G. Detection in Escherichia coli of the genes encoding the major virulence factors, the genes defining the 0157:H7 serotype, and components of the type 2 shiga toxin family by multiplex PCR. Journal of Clinical Microbiology, Washington, v.40, n.10, p.36133619, 2002. 